\title{
Cambios en la temporatidad y en la espacialidad de la comunicación
}

\section{Antecedentes de la "Ecología Gris"}

Temprano es el análisis de Vilém Flusser que podría llamarse "ecológico", extrayéndole a este comcepto la connotación simplemente de lo "verde", y trasladándolo a la "comunicación", "la imagen visual" y la "filosofía". La tradicional separación antropológica entre naturaleza y cultura, tan cara a una larga tradición que, en algunos momentos, funciona como perspectiva metodológica, es decir, la facilidad estructuralista de separar en clasificaciones las complejidades sócioculturales, $y$, en otros, como una deriva teóricoconceptual que, al intentar distanciarse para mantener la "objetividad" concibe al otro como una alteridad emparentada con la naturaleza, la que, a su vez, le da sustento. La "mismidad" del antropólogo lo aparta de la alteridad del otro, natural y no cultural.

El "colegio invisible" o "escuela de Palo Alto" ya había "visibilizado" que la naturaleza y la cultura más que instancias separadas confluyen en un enfoque ecológico, cuestionando esa tradición antropológica que planteaba la separación como clasificación estructural. En fechas más recientes, Félix Guattari (1996: 33), sostiene que "hoy menos que nunca puede separarse la naturaleza de la cultura, y hay que aprender a pensar transversalmente" las interacciones entre ecosistemas, maquinosfera y cultura.

Así las cosas, el ser humano, para el colegio invisible, tiene una esencia biológica, diría abusando de los conceptos que es "un mono avanzado". El origen y la base biológica se encuentran aún presentes y tienen sus orígenes miles de años atrás, desde el momento mismo del inicio del proceso de hominización. Esto significa que el ser humano conserva aún en su esencia comportamientos, actitudes y manifestaciones ancestrales. Como indica Norval Baitello jr (2005: 71), las investigaciones, de los llamados siste-mas afectivos entre primates superiores, de los cuales los humanos formamos parte, permiten aclarar aspectos fundamentales respecto de la naturaleza y de la motivación de los vínculos primordiales de sus sistemas comunicativos. "As ciências da comunicação não terão nada a perder quando deixarem de lado seu antropocentrismo e pássarem a considerar, estudar e compreender outros sistemas comunicativos não humanos" (Baitello, 2005: 72). En términos de Michel Serres (2011: 31), refiriéndose a la experiencia de los trepadores de alta montaña, "Homo erectus, el hombre de pie, reciente, vuelve a aquel del que desciende, el cuadrumano arcaico". Mono, araña, molusco, Analógicamen-te, trepan la alta montaña.

La comunicación, para la interdisciplinaria Palo Alto (donde confluían comunicólogos, antropólogos/as, psicólogos, cibernéticos), era ese espacio de confluencia. Por ello, como afirmaba Paul Watzlawick, no se puede no comunicar. No obstante, para Palo Alto (Bateson, Hall, Watzlawick), como fundamento del "interaccionismo simbólico", esas

\footnotetext{
1 Víctor Silva Echeto - Possui graduação em Licenciatura en Ciencias de la Comunicación - Universidad de La Republica Oriental Del Uruguay (1999), mestrado en Comunicación pela Universidade Internacional de Andalucia (2000) e doutorado em Estudios Culturales: Literatura y Comunicación - Universidad de Sevilla (2003). Atualmente é professor/investigador - Universidad de Playa Ancha, professor - Universidad Austral de Chile e professor - Universidad de Artes y Ciencias Sociales, e professor/investigador estrangeiro da FAPESP.
} 
relaciones y vínculos (de última comunicar es vincular) son la base de los intercambios personales. Comunicación, en ese contexto, no es unicamente mediaciones técnicas (como sostenían el funcionalismo o la teoría matemática de la información) sino, fundamentalmente, mediaciones primarias (en términos de Pross) e interpersonales.

El recorrido se inicia en 1959 cuando el psiquiatra D. Jackson, funda el Mental Research Institute, tres años después se integra Paul Watzlawick, ambos, en esos años, inician las investigaciones sobre la esquizofrenia y diversas patologías relacionadas con la comunicación. Desde esas pesquisas surgirá una teoría de la comunicación interpersonal que tendrá gran relevancia en las dos deca-das siguientes.

El contexto del interaccionismo simbó-lico, a su vez, no se reducía a las relaciones interpersonales sino que, además, amplió el concepto de cultura hacia el de interculturalidad. Es así como Edward T. Hall, quien formó parte del colegio invisible, en las primeras décadas del siglo XX, propuso la noción de interculturalidad, para referirse a las distancias que se producen entre las culturas y como éstas se amplían y extienden en contextos de conflictividad cultural. Hoy, en el siglo XXI, junto con las emociones, son nociones principales para los estudios de la comunicación (Rodrigo Alsina, 1999).

El discípulo de Marshall Mc Luhan, Barrington Nevitt, escribe The ecology of communication, entrados los años "80, donde planteará un enfoque que vincula la ecología a los aspectos técnicos de la comunicación. Por la misma época, David L. Altheide publica $A n$ ecology of commu-nication. Cultural formats of control, donde se refiere a las relaciones de poder y al control social producido por los medios. Es el volumen colectivo del International Institute of Communications, Cultural ecology. The changing dynamics of communication, que analiza las repercusiones socio-cultu-rales de las Tecnologías de la
Información y de la Comunicación en diversas regiones del mundo.

\section{Ecología "gris"}

Si se cruza el Atlántico, se encuentra con que los estudios "ecológicos", en Europa, como en Estados Unidos, son tardíos. Hay que destacar, al respecto, los aportes que se producen tanto en Alemania como en Francia, y, posteriormente en España por parte Vicente Romano (2004).

En el primer país, se destacan las contribuciones de Mathias Donath (1998), quien extiende el concepto de Mit-Mensch al de Mit-Welt, es decir, no solo se refiere al prójimo humano sino, también, al prójimo natural, al entorno. Barbara Mettler von Meibom (1990), aborda la ecología, desde una perspectiva sistémica, es decir, desde una mirada integrada entre sistemas tecnológicos, sociales, ecológicos. Radicalizando el planteamiento y llegando a proponer, en algunos momentos, "el derecho a la no asequibilidad y a zonas o tiempos $\sin$ tecnologías a fin" de protegerse "de la omnipresente agresión medial" (Romano, 2004: 9).

La posibilidad de separar el enfoque ecológico, simplemente, como protección de lo verde, se le debe, entre otros, en Francia a Paul Virilio. Este urbanista, la denomina la ecología gris, porque no tiene color. Se presenta, así, como un progreso.

\footnotetext{
"Todos se alegran y saltan de júbilo cuando se anuncia un tren aún más rápido o un avión aún más veloz que el anterior. Con el descubrimiento de las armas atómicas todos gritaban que esto era espantoso, repulsivo. Apenas si sucede esto cuando se inventa un auto todavía más rápido, o cualquier cosa que sea aún más rápida que cualquier otra, porque es vitoreada casi absolutamente por todos, sin importar que esta contracción nos presione y asfixie" (Virilio, 1999: $\mathrm{s} / \mathrm{p})$.
}

Todavía no hay una sensibilización por las dimensiones de esta ecología gris, ni con sus, para Virilio (1999: s/p), “devastadoras 
consecuencias". Con frecuencia, el urbanista francés, le ha planteado "a los verdes" que se "pondría de su lado, tan pronto se interesasen en la ecología gris". Hasta estas décadas "sólo han hablado del espacio, pero no del tiempo. Si bien, todo espacio es un espacio de tiempo; y toda condición de vida, todo espacio ecológico ha de habérselas con tamaños y proporciones". Con esto, lo que hace Virilio (1999: s/p), es moverse "en las proporciones de un arquitecto, quien se halla en una cierta relación con las cosas. Las proporciones y relaciones hoy se han contraído, tele transmitido, van derecho a su desaparición". En la medida que "esto se mantenga sin ser comprendido, tampoco se habrán planteado todas las preguntas de las ciencias (...) Los conocimientos técnicos son un drama. En el siglo XIX, la ciencia técnica parecía ser todavía un avance, comparándolo con el diario vivir de los campesinos o de los trabajadores. Un siglo más tarde esto es tan sólo un drama, y símbolos de esto son ya el hundimiento del Titanic o el accidente del reactor de Chernobyl". Décadas después de esa entrevista realizada a Paul Virilio, en 2011, el accidente en Japón de Fukushima, luego de un terremoto y maremoto, volvió a poner frente a frente al ser humano y sus técnicas y la naturaleza y sus técnicas. La ecología gris retornó. La catastrofe no fue producida por el terremoto o maremoto sino por la radiación emitida por la central de Fukushima.

La aceleración y la velocidad, llevan a la pérdida de la geografía en detrimento de la dromografía (dromo es velocidad), el espacio se encoge y el tiempo se acelera. El entorno se transforma en comtorno sobre el que se circula. Paradójicamente, en las megalópolis se produce el efecto inverso. En una megaciudad como São Paulo, con más de 10 millones de habitantes, 20 millones si se incluyen las ciudades satélites y más de 7 millones de coches, trasladarse de un sitio a otro lleva un promedio de 3 horas diarias. La vida cotidiana transita entre helicópteros (es la ciudad del mundo que tiene la mayor cantidad) y metros o subtes, sobre o bajo la tierra, como pájaros de hierro o topos eléctricos. Paralelamente, en los metros o subtes o en las fiestas masivas - como la parada gay - de la megaciudad, se experimenta la acumulación de cuerpos como com-juntos de carnes masacradas por la falta de espacio o, en algunos casos, por su aniquilación.

\section{De la ecología gris a la ecosofía}

Gilles Deleuze y Félix Guattari (2000), utilizan diversas terminologías de la naturaleza para referirse a un pensamiento liberador pero, también, opresor. Mesetas, rizomas, enfrentados a árboles. Horizontalidad y redes a jerarquías. También, son influenciados, a diferencia de lo que se considera en América Latina como pensamiento colonizador, por teóricos de las Américas como Maturana y Varela con nociones como las de autopoiesis, es decir, como subjetividades inmanentes que se auto-producen.

Guattari, posteriormente, continuará con una deriva aún más ecológica, pasando de ésta a la ecosofía. Es decir, en lugar de continuar analizando la contaminación ambiental desde una perspectiva tecnocrático económica $\mathrm{o}$ funcional cuantitativa, asume su estudio desde una óptica ético-política, la que llama, ecosofía. De ahí su planteamiento sobre las tres ecologías: del medioambiente, de la cultura y de la subjetividad humana.

La respuesta a la crisis ecológica "sólo podrá hacerse a escala planetaria y a condición de que se realice una auténtica revolución política, social y cultural que reoriente los objetivos de la producción de los bienes materiales e inmateriales". Así las cosas, esa "revolución no sólo deberá concernir a las relaciones de fuerzas visibles a gran escala, sino también a los campos moleculares de sensibilidad, de inteligencia y de deseo" (Guattari, 1996: 9).

Guattari destaca dos modos dominantes de valoración de las colectividades humanas, el 
primero, es "imperio de un mercado mundial", un Capitalismo Mundial Integrado, "que lamina los sistemas particulares de valor, que sitúa en un mismo plano de equivalencia: los bienes materiales, los bienes culturales, los espacios naturales"; el segundo, "sitúa el conjunto de las relaciones sociales y de las relaciones internacionales bajo el dominio de las máquinas policiales y militares". En esa doble pinza, los Estados-naciones, ven "cómo su papel tradicional de mediación se reduce cada vez más, y a menudo se ponen al servicio conjugado de las instancias del mercado mundial y de los complejos militardoindustriales" (Guattari, 1996: 11- 12). En un texto anterior, junto con Rodrigo Browne (Silva- Browne, 2007), nos referíamos, en el caso de las diversas crisis ecológicas producida en el sur de Chile ante la instalación de una planta de celulosa o al grito de que "se vayan todos" que emanaba de las voces populares en Quito o en La Paz, al "pensar - sinEstado" (Lewkowicz, 2004), o, el "pensar sin-comunicación".

Para Guattari (1996: 12- 13), "el antiguo igualitarismo de fachada de mundo comunista da paso así al serialismo, massmediático ${ }^{\text {ee }}$ (el mismo ideal de standing, las mismas modas, el mismo tipo de música rock, etc.)". En esas palabras se escuchan los ecos Frankfurtianos de las "industrias culturales", concepto transformado en "integrado" y en "positivo" por la post-industria de la gestión y la administración cultural. Este último es otro de los tópicos que debería de cubrir críticamente una nueva mirada sobre la ecología de la comunicación y de la cultura.

Para esa mirada crítica, "es concebible, por el contrario, que la nueva referencia ecosófica indique líneas de recomposición de las praxis humanas en los dominios más variados". A las más diversas escalas individuales y colectivas, tanto en lo que respecta a la vida cotidiana como a la reinvención de la democracia, en el registro del urbanis-mo, de la creación artística, del deporte, siempre se trata de interesarse por lo que podrían ser dispositivos de producción de subjetividad que van en el sentido de una resingularización individual y/o colectiva más bien que en el de una fabricación mediática "sinonimo de angustia y de desesperación” (Guattari, 1996: 18-19).

Estas perspectivas no excluyen la definición de objetivos unificadores tales como la lucha contra el hambre en el mundo, el freno de la desforestación o la proliferación ciega de las industrias nucleares. "Ahora bien, aquí ya no puede tratarse de consignas estéreotipadas, reduccionistas, que eliminan otras problemáticas más singulares y que implican la promoción de líderes carismáticos", también, pone en cuestionamiento la "industria de la ecología" llevada adelante por algunas ONGs.

Una misma intención ético-política atraviesa los problemas del racismo, del falocentrismo, de los desastres legados por un urbanismo pretendidamente moderno, de una creación artística liberada del sistema del mercado, de una pedagogía capaz de inventar sus mediadores sociales. Estas problematicas son, a fin de cuentas, la de la producción de existencia humana en los nuevos contextos históricos.

"La ecosofía social consistirá, pues, en desarrollar prácticas especificas que tiendan a modificar y a reinventar formas de ser en el seno de la pareja, en el seno de la familia, del contexto urbano, del trabajo", entre otros aspectos (Guattari, 1996: 19).

"Por su parte, la ecosofía mental se verá obligada a reinventar la relación del sujeto con el cuerpo, el fantasma, la finitud del tiempo, los "mistérios" de la vida y de la muerte. Se verá obligada a buscar antídotos" a la uniformización mediática y telemática, "al conformismo de las modas, a las manipulaciones de la opinión por la publicidad, los sondeos". Su forma de actuar se aproximará más a la del artista, la del performance, la del intervencionista en contextos socioculturales, "que a la de los profesionales "psy" (psicoanalistas), "siempre obsesionados 
por un ideal caduco de cientificidad" (Guattari, 1996: 19-20).

Guattari, siguiendo la lógica conceptual iniciada junto con Deleuze, se refiere a los "componentes de subjetivación": que "comduciría necesariamente a reexaminar la relación entre el individuo y la subjetividad, y, en primer lugar, a separar claramente los comceptos". Esos vectores de subjetivación no pasan necesariamente por el individuo que está en posición de "terminal" respecto a procesos que implican grupos humanos, conjuntos socioeconómicos o máquinas informáticas. "Así, la interioridad se instaura en el cruce de múltiples componentes relativamente autónomos los unos en relación con los otros y, 11 e gado e 1 caso, francamente discordantes" (Guattari, 1996: 20).

Del paradigma cientificista, Guattari, propone el pasaje al ético-estético. "Temporalidades humanas y no huma-nas". Por estas últimas entiende "el desplegamiento o, si se quiere, el dêspliegue, de devenires animales, de deve-nires vegetales, cósmicos, pero también de devenires maquínicos, correlativos de la aceleración de las revoluciones tecnológicas e informáticas" (Guattari, 1996: 26).

Plantea reagrupar en cuatro principales regímenes semióticos los instrumentos sobre los que reposa el Capitalismo Mundial Integrado:

\footnotetext{
- las semióticas económicas (instrumentos, monetarios, financieros, contables, de decisión);

- las semióticas jurídicas (título de propiedad, legislación y reglamentaciones diversas...);

- las semióticas técnico-científicas (planes, di a gramas, programas, estudios, investigaciones...);

- las semióticas de subjetivación, algunas de las cuales coinciden con las que acaban de ser enumeradas, pero a las que convendría añadir muchas otras, tales como las relativas a la arquitectura, el urbanismo, los equipamientos colectivos, (Guattari, 1996: 43-44).
}

Gregory Bateson propuso una "ecología de las ideas" que no puede ser circunscrita al dominio de la psicología de los individuos, sino que se organiza en sistemas o "espíritu" (minds) cuyas fronteras ya no coinciden con los individuos que participan en él.

Pero Guattari deja de estar de acuerdo con Bateson, "cuando convierte la acción y la enunciación en simples partes del subsistema ecológico llamado contexto". Por su parte, considera que la "toma de contexto existencial" depende de una praxis, que se instaura en ruptura con el "pretexto" sistémico. No existe una jerarquía de conjuntos que sitúe y localice a un determinado nivel las componentes de enunciación. Éstas se componen de elementos heterogéneos que adquieren consistencia y persistencia común cuando superan los umbrales constitutivos de un mundo en detrimento de otro.

El principio que guía a las tres ecologías consiste, en que los Territorios existenciales a los que se confrontan los componentes de subjetividad "no se presentan como en-sí, cerrados sobre sí mismos, sino como un para-sí precario, acabado, finitizado, singular, singularizado, capaz de bifurcarse, en reiteraciones estratificadas y mortíferas o en apertura procesual a partir de praxis que permiten hacerlo ,habitable ${ }^{\text {ee }}$ por un proyecto humano". Esa apertura práxica constituye la esencia de ese arte de la eco o del oikos "que subsume todas las maneras de domesticar". No se trata de erigir reglas universales como guía de esas praxis, sino, a la inversa, de "extraer las antinomias principales entre los niveles ecosóficos $\mathrm{o}$, si se prefiere, entre las tres visiones ecológicas, los tres vasos discriminantes": ambientales, subjetivos y socio-culturales (Guattari, 1996: 53).

Lógica que podría denominarse del "tercero incluido". En el caso particular de la ecología del fantasma, lo que se requiere en cada tentativa de anotación cartográfica es la elaboración de un soporte expresivo singular o más exactamente, singularizado. Ese soporte es el cuerpo. 
Como indica Michel Serres (2011: 33), en variaciones sobre el cuerpo, "el primerísimo cogito fue un proyecto de refugio para encontrar la bola perdida; por eso buscamos un techo, por eso habitamos. El humano, de pie, acaba de nacer".

\section{Habitar ambientes}

- Oikos casa habitabilidad en Vicente Romano.

- Midia primaria: presencial. Capilaridad 1: Norval;

- Midia secundaria: escritura. Capilaridad 2. Jacques Derrida: Gramatología; Michel Serres cuerpo de la escritura;
- Midia terciaria: electricidad. Serpientes. Warburg.

- Los ambientes en Flusser: las tres catástrofes.

- Crítica a Flusser a través del nomadismo en Deleuze. Movimiento no significa trayecto. Ejemplo en el cine

\section{Referências Bibliográficas}

"Temos várias maneiras de relacionar-nos com a natureza, algumas das quais podem ser chamadas "sobrenaturais", "teóricas" ou "perspectivas" (segundo os nossos vários gostos). Uma de tais maneiras é encarar a natureza como se fosse mapa". Vilém Flusser.

BAITELLO, Norval. O animal que parou os relógios. 2a , ed. S. Paulo: Annblume,1999.

"A cultura de ouvir". In Bentes, I. Zaremba, L. Rádio Nova. Constelações da radiofonia contemporânea. Rio de Janeiro: Publique, 2005.

FLUSSER, Vilém. A história do Diabo. São Paulo: Martins, 1965.

. Die Schrift (A Escrita) $4^{\mathrm{a}}$ ed. Göttingen: Immatrix, 1992.

Ficções Filosóficas. Editora da Universidade de São Paulo. 1998.

. Natural:mente: Vários acessos ao significado de natureza. Ensaios brasileiros, filosofia da natureza. São Paulo. Ed. D. cidades, 1979.

. Pós-história: vinte instantâneos e um modo de usar. D. cidades, SP. 1983.

GUATTARI, Felix. Psychanalyse et Transversalité. Paris: François Maspero, 1996.

SERRES, Michel. Os Cinco Sentidos: filosofia dos corpos misturados. Rio de Janeiro, B. Brasil. 2011. 